\title{
Chronotherapy with low-dose modified-release prednisone for the management of rheumatoid arthritis: a review
}

This article was published in the following Dove Press journal:

Therapeutics and Clinical Risk Management

21 November 2016

Number of times this article has been viewed

\author{
Stefano Paolo Beltrametti' \\ Aurora lanniello² \\ Clara Ricci ${ }^{3}$ \\ 'Department of Rheumatology, \\ S. Andrea Hospital, Vercelli, \\ ${ }^{2}$ Rheumatology Outpatient Clinic, \\ Novara, ${ }^{3}$ Primula Multimedia S.p.A, \\ Pisa, Italy
}

\begin{abstract}
To date, rheumatoid arthritis (RA) remains a debilitating, life-threatening disease. One major concern is morning symptoms (MS), as they considerably impair the patients' quality of life and ability to work. MS change in a circadian fashion, resembling the fluctuations of inflammatory cytokines such as interleukin-6, whose levels are higher in RA patients compared to healthy donors. Conversely, serum levels of the potent anti-inflammatory glucocorticoid cortisol are similar to that of healthy subjects, suggesting an imbalance that sustains a proinflammatory state. From a therapeutic point of view, administering synthetic glucocorticoids (GCs) to RA patients represents an optimal strategy to provide for the inadequate levels of cortisol. Indeed, due to their high efficacy in RA, GCs remain a cornerstone more than 60 years after their first introduction, and despite the development of a wide range of targeted agents. However, to improve safety, low-dose GCs have been introduced, that have demonstrated high efficacy in reducing disease activity, radiological progression, and improving patients' signs and symptoms especially in early RA when added to conventional disease-modifying antirheumatic drugs. A further improvement has been provided by the development of modified-release prednisone, which, by taking advantage of the circadian fluctuations of inflammatory cytokines, cortisol and MS, is given at bedtime to be released approximately 4 hours later. Several studies have already demonstrated the efficacy of this agent on disease activity, MS, and quality of life in the setting of established RA. Moreover, preliminary studies have shown that this new formulation not only has no impact on the adrenal function, but likely improves it. This review is a comprehensive, updated summary of the current evidence on the use of GCs in RA, with focus on the efficacy and safety of low-dose prednisone and modified-release prednisone, the latter representing a rational, cost-effective, and tailored approach to maximize the benefit/risk ratio in RA patients.
\end{abstract}

Keywords: glucocorticoids, rheumatoid arthritis, modified-release prednisone, safety, efficacy, adrenal function

\section{Introduction}

Rheumatoid arthritis (RA) is a systemic autoimmune disease, characterized by chronic inflammation of the synovial membrane that progressively leads to joint destruction and tissue damage. The interplay of B- and T-cells, macrophages, chondrocytes, osteoclasts, and synovial cells, along with the release of a plethora of growth factors and cytokines (eg, tumor necrosis factor alpha, interleukin [IL]-1 $\beta$, IL-6, IL-8, IL-12, and IL-17) triggers the immune-inflammatory process typical of the disease. ${ }^{1,2}$ Damage of joints and extra-articular organs may cause severe functional disabilities, reduced quality of life (QoL), and increased mortality. ${ }^{3-6}$ In particular, morning symptoms (MS) such
Correspondence: Stefano Paolo Beltrametti

Department of Rheumatology, S. Andrea Hospital, Corso Mario Abbiate, 2I, I3100 Vercelli, Italy Tel +390161593496

Fax +39016 I593860

Email paolo.beltrametti@aslvc.piemonte.it 
as stiffness, fatigue, swelling, and pain considerably affect patients' QoL and ability to work. ${ }^{7-11}$ Therefore, in the management of RA, it is critical to develop treatment strategies that are able to counteract the impairment of morning functions.

Several studies have shown that RA symptoms change in a circadian fashion, being worst in the morning (Figure 1A-D). ${ }^{12-15}$ Circadian rhythm is generated by the central clock in the suprachiasmatic nucleus of the hypothalamus, from where the timing signals are transferred to the immune system via the hypothalamic-pituitary-adrenal (HPA) axis. ${ }^{16,17}$ This, in turn, produces the steroid hormones
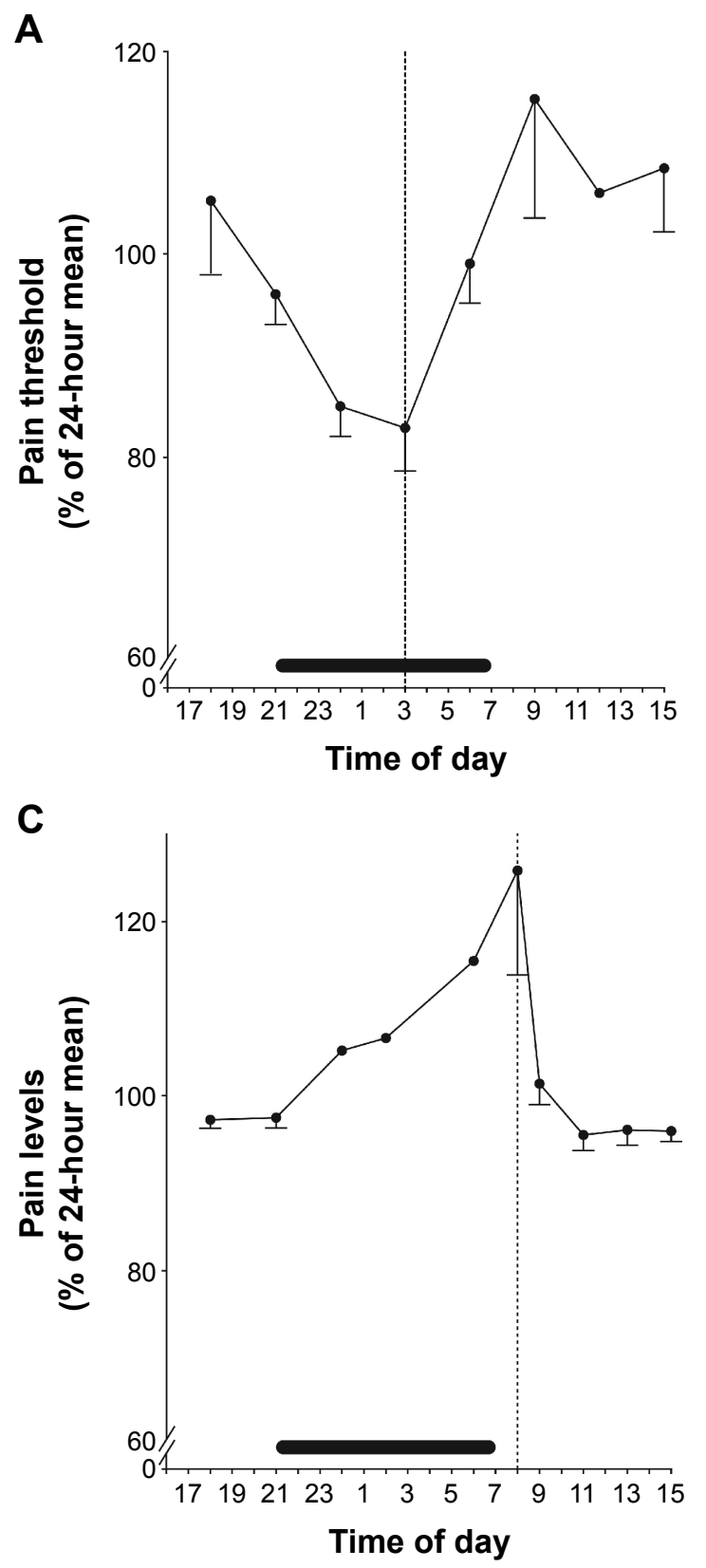

glucocorticoids (GCs), such as the potent anti-inflammatory hormone cortisol, that are released in a circadian fashion under the control of the central clock. ${ }^{17}$ In RA patients, the circadian curve of serum cortisol is similar to that observed in healthy subjects (Figure 2A), although depending on the degree of inflammation (Figure 2B), but the levels of the inflammatory cytokines, tumor necrosis factor alpha and IL-6, are higher in the early hours (Figure 2C and D). ${ }^{15}$ Hence, it is likely that, in RA, cortisol secretion is insufficient to counteract the circadian fluctuations of these molecules. One strategy to supply the inadequate levels of cortisol

B

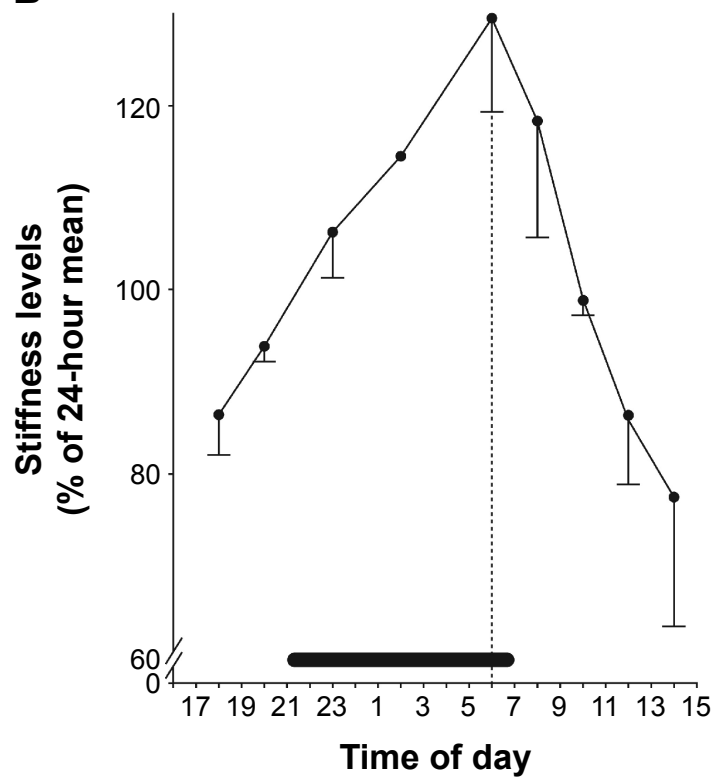

D

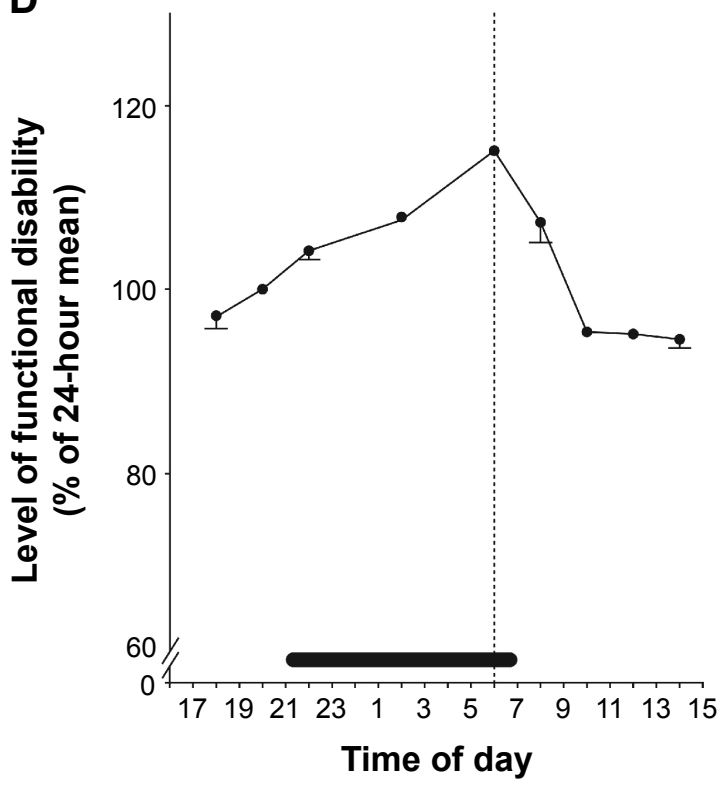

Figure I Circadian rhythm of (A) pain measures in healthy subjects and of (B) stiffness, (C) pain levels, and (D) functional disabilities in rheumatoid arthritis patients. Notes: Values are expressed as the mean and standard error of mean. Horizontal bars starting at 21.00 ( 9 pm) indicate sleeping time. Vertical dotted lines show the peak or minimum value for the respective parameter. Republished with permission of John Wiley and Sons Inc, from Straub RH, Cutolo M. Circadian rhythms in rheumatoid arthritis: implications for pathophysiology and therapeutic management. Arthritis Rheum. 2007;56(2):399-408; permission conveyed through Copyright Clearance Center, Inc. ${ }^{15}$ 

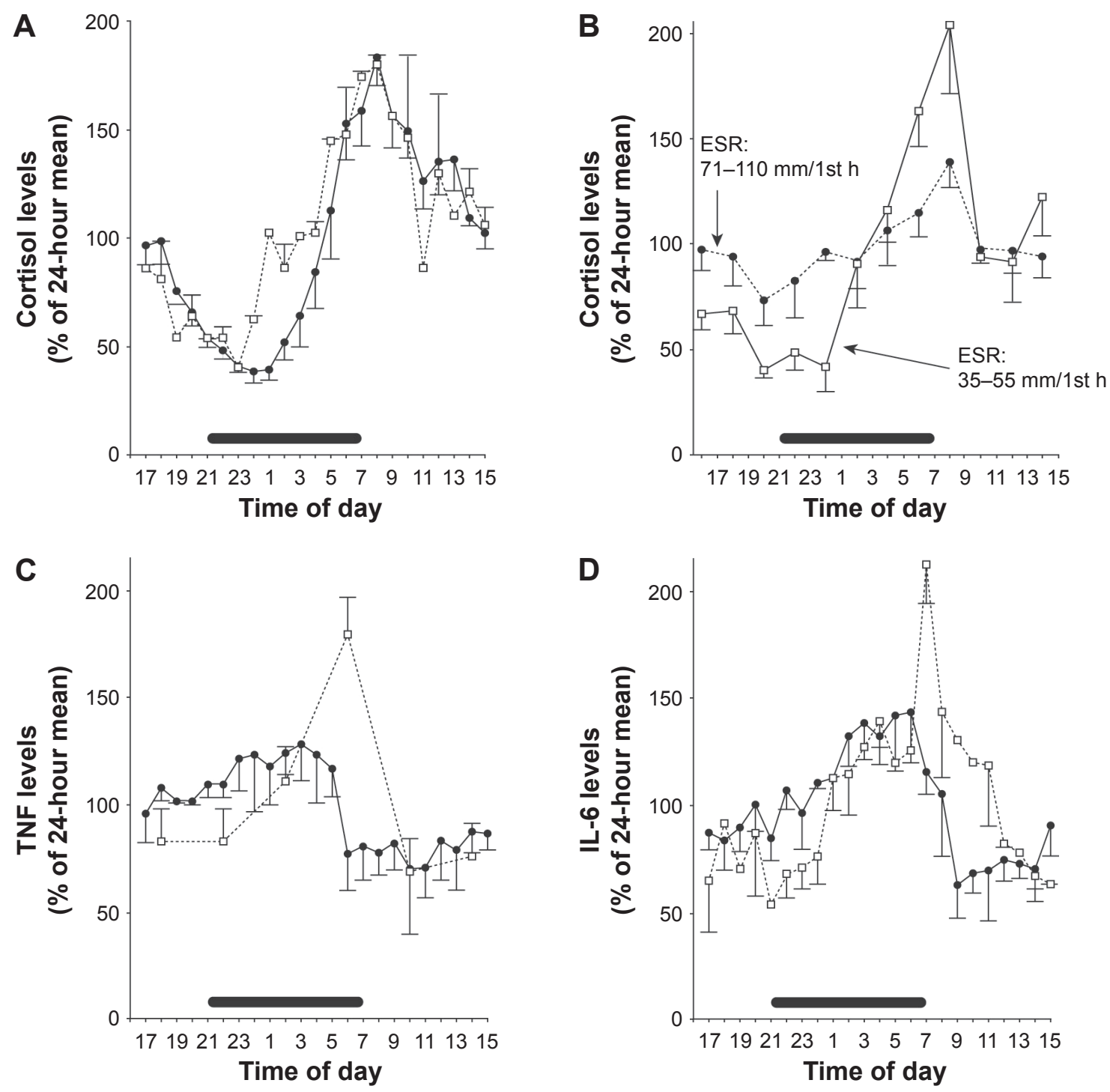

Figure 2 Circadian rhythm of (A) cortisol in healthy subjects (solid lines) and in patients with RA (dotted lines), and (B) in RA patients according to the degree of inflammation (high or low), as determined by ESR; 24-hour serum level variation of (C) TNF- $\alpha$ and (D) IL-6 in healthy donors (solid lines) and in RA patients (dotted lines). Notes: Values are expressed as the mean and standard error of mean. Horizontal bars starting at 21.00 ( 9 pm) indicate sleeping time. Republished with permission of John Wiley and Sons Inc, from Straub RH, Cutolo M. Circadian rhythms in rheumatoid arthritis: implications for pathophysiology and therapeutic management. Arthritis Rheum. 2007;56(2):399-408; permission conveyed through Copyright Clearance Center, Inc. ${ }^{15}$

Abbreviations: ESR, erythrocyte sedimentation rate; IL-6, interleukin-6; RA, rheumatoid arthritis; TNF- $\alpha$, tumor necrosis factor- $\alpha$.

relies on the administration of synthetic GCs which, more than 60 years after their introduction in the treatment of RA, ${ }^{18,19}$ remain a therapeutic mainstay of this disease. Yet, due to the adverse events (AEs) observed in patients treated with GCs, the use of low doses ( $\leq 10 \mathrm{mg} /$ day) has been adopted, ${ }^{20,21}$ which have been demonstrated to be effective in improving clinical, functional, and structural outcomes. ${ }^{22,23}$ This is well established in early RA, in which the addition of low-dose prednisone to standard disease-modifying antirheumatic drugs (DMARDs) such as methotrexate (MTX) induces a more rapid and persistent benefit than DMARD monotherapy. ${ }^{24-29}$ However, concerns remain on the safety profile of the long-term use of low-dose GCs. In an attempt to maximize the benefit/risk ratio, the timing of $\mathrm{GC}$ administration has been optimized ${ }^{30}$ and a new formulation of prednisone (modified-release [MR] prednisone) has been developed, that is capable of significantly reducing IL-6 levels and MS compared to control treatments, without increasing the risk for adrenal suppression. ${ }^{31-37}$

The aim of this review is to provide a comprehensive summary of the current evidence on the use of GCs in RA, focusing, in particular, on the efficacy and safety of lowdose prednisone in combination with MTX in patients with early disease, and of MR prednisone in established disease. The development of this new formulation of prednisone is emerging as a rational, cost-effective strategy to target the interplay between the HPA axis and the immune system, without impacting on the adrenal function. 


\section{GC mechanism of action}

GCs are steroid hormones physiologically produced in the adrenal cortex. They represent the final product of HPA axis, which orchestrates the stress response. ${ }^{16,17}$ Among these, cortisol, besides controlling processes such as glucose and lipid metabolism, regulates the inflammatory and immune responses as part of stress adaptation.

Due to their hydrophobic structure, GCs can easily pass the cell membrane and enter the cell, where they exert their effects via genomic and nongenomic mechanisms. In the cytosol, GCs bind to the ubiquitous, wild-type form of the GC receptor (GR $\alpha$ ), which, under basal conditions, forms a complex with various chaperons that prevent its translocation to the nucleus. Upon binding to GC, the resulting complex translocates to the nucleus, where it binds to specific DNA sequences ( $\mathrm{GC}$ response elements) in the promoter region of target genes, either activating ("transactivation") or repressing ("transrepression") their transcription. In this regard, the current evidence supports the anti-inflammatory activity of GCs as mostly depending on the inhibition of the expression of pro-inflammatory genes, rather than on the transcription of anti-inflammatory effectors. The ligand-activated GR $\alpha$ can modulate the expression of several genes also by physically interacting with transcription factors such as activator protein-1 and nuclear factor- $\mathrm{\kappa B}$, preventing their association with DNA, or by remodeling chromatin through recruitment of histone deacetylases or interaction with cofactors with histone acetyltransferase activity, finally inhibiting the transcription of pro-inflammatory genes.

On the other hand, GCs may exert rapid nongenomic effects through different mechanisms, such as the nonspecific interaction with cellular membranes, the binding to cytosolic GR $\alpha$, and the specific interaction with a membrane-bound GR. However, the presence of multiple GR isoforms and the occurrence of different post-translational modifications further complicate the understanding of the response to GCs.

As already stated previously, GCs are released in a circadian fashion. Interestingly, a recent study demonstrated that the heterodimer composed of the circadian locomoter output cycles kaput (CLOCK) and the brain-muscle-arnt-like protein 1 (BMAL1) transcription factor can suppress the transcriptional activity of GR $\alpha$ in vitro through acetylation of a stretch of lysines. ${ }^{38}$ CLOCK-BMAL1 regulates the circadian oscillations of the expression of various genes: in the case of GR $\alpha$, the CLOCK-BMAL1-mediated acetylation reduces the binding of the ligand-receptor complex to the GC response elements on target genes, and also impairs its translocation to the nucleus..$^{38}$ In vivo, the acetylation status of GR $\alpha$ in mononuclear cells from healthy donors has been shown to be higher in the morning than in the evening, just like the messenger RNA levels of CLOCK and BMAL1. ${ }^{39}$ These results may account, at least in part, for the circadian oscillations of sensitivity to endogenous GCs, which is reduced in the morning and increased at night. Indeed, in RA, the successful therapeutic outcome associated with the administration of synthetic GCs during the evening hours, and in particular of MR prednisone, may depend at least in part on the increased sensitivity of immune cells to GCs, which, in turn, may be due to a decrease of the acetylation status of GR $\alpha$ in the evening. ${ }^{17}$

\section{Low-dose prednisone combined with MTX in early RA: efficacy and European League Against Rheumatism recommendations}

As the course of RA is characterized by alternating phases of remission and exacerbation, long-term treatment is usually required to prevent disease flares. However, despite major progresses in the treatment of RA, only a minority of patients achieve sustained clinical remission. Evidence supports the correlation between a shorter time to remission and a better outcome, ${ }^{40-44}$ and therefore the treat-to-target approach has been introduced in the management of RA by the 2010 European League Against Rheumatism (EULAR) recommendations. ${ }^{45}$ Accordingly, an aggressive therapy should be initiated soon after diagnosis, and drugs escalated to pursue clinical remission or, if this is not feasible, lowdisease activity. The best way to achieve the primary goal of clinical remission is by abrogating inflammation. ${ }^{46}$

Currently, the therapeutic armamentarium of RA includes conventional DMARDs such as MTX, biologics, and antiinflammatory agents. The most frequently administered anti-inflammatory, immunosuppressive drugs are synthetic GCs, which, despite the concerns on their long-term safety, are still used in $40 \%$ to $84 \%$ of RA patients. ${ }^{47,48}$ In particular, compelling evidence supports the higher efficacy of the combination of low-dose GCs with DMARDs, compared to DMARDs alone, in suppressing disease activity, slowing radiological progression, and relieving symptoms, likely as a consequence of better inflammation control. ${ }^{22,23}$ Although data obtained in established disease do not allow a clear conclusion, ${ }^{49}$ the vast majority of the studies investigating the efficacy of the combination in early RA support its beneficial effect in this setting. ${ }^{24-29}$ The characteristics of the key trials are summarized in Table 1. Overall, the addition of as low 


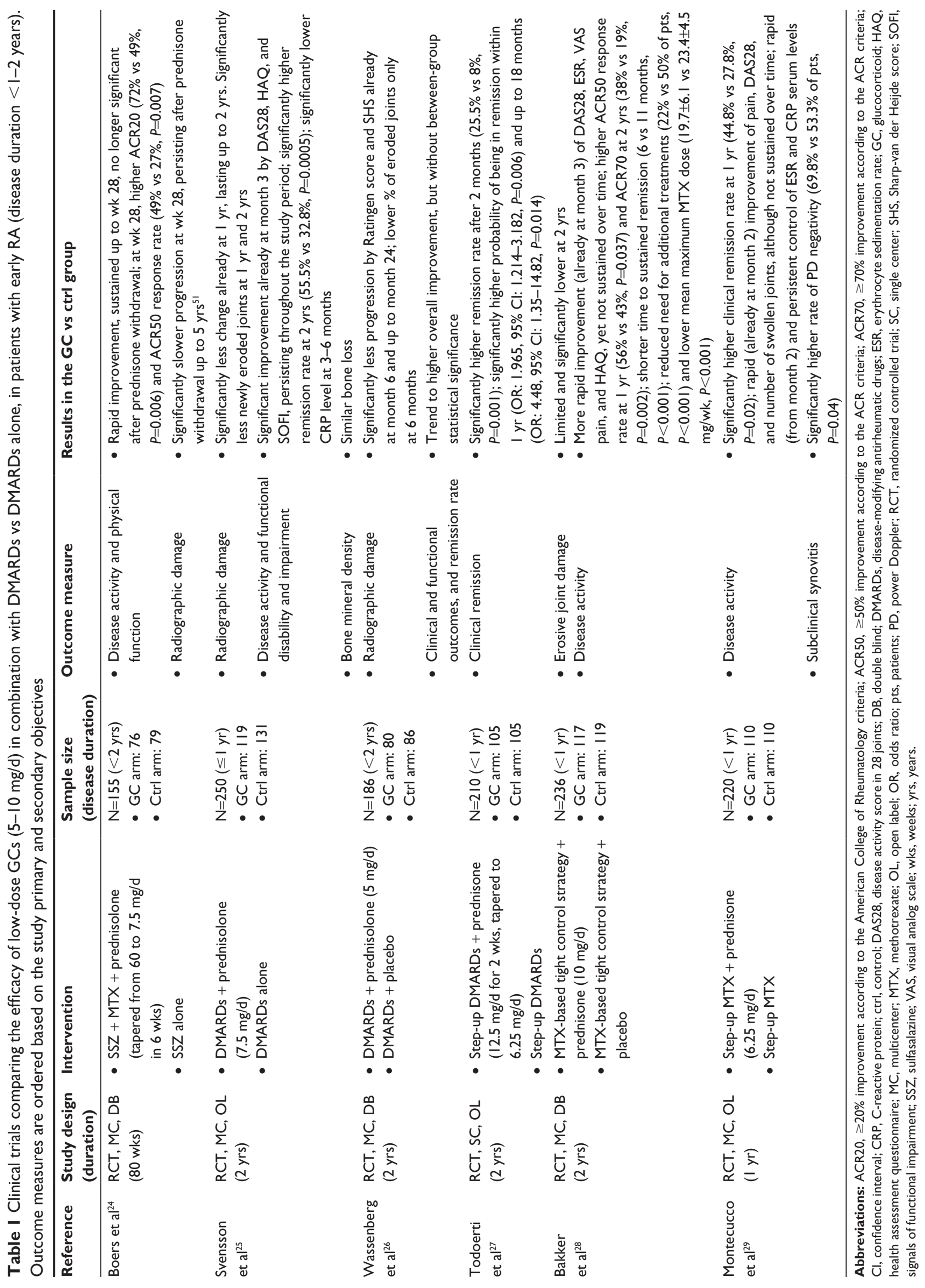


as $5 \mathrm{mg}$ /day prednisone to DMARDs was able to rapidly and significantly delay radiographic progression and prevent joint erosion compared to DMARD monotherapy, and this effect was sustained over time. ${ }^{24-26,28,50}$ Moreover, low-dose GCs induced a rapid improvement of disease activity and physical function, but this effect was generally temporary regardless of the regimen adopted. ${ }^{24,26,28,29}$ The only exception is the trial from Svensson et al, in which the significant clinical benefit provided by $7.5 \mathrm{mg}$ /day prednisolone added to DMARDs persisted throughout the 2-year study period. ${ }^{25}$ As for the acute-phase response, the few available data demonstrated a rapid control of inflammation by low-dose GCs (as indicated by the rapid decrease of erythrocyte sedimentation rate and/ or C-reactive protein levels), but of a variable duration. ${ }^{25,29}$ Conversely, American College of Rheumatology (ACR) response and clinical remission were significantly higher and mostly durable in prednisone-treated patients. ${ }^{24-29}$ In particular, the Combinatietherapie Bij Reumatoide Artritis (COBRA) trial reported that at week $28,72 \%$ and $49 \%$ of patients in the prednisolone group had achieved ACR20 and ACR50 response, respectively, vs 49\% $(P=0.006)$ and $27 \%(P=0.007)$ in the control group. ${ }^{24}$ Also, the Computer Assisted Management in Early Rheumatoid Arthritis-II trial showed a higher ACR50 response rate at 1 year (56\% vs 43\%, $P=0.037)$ and ACR70 at 2 years ( $38 \%$ vs $19 \%, P=0.002)$, as well as a significantly shorter time to sustained remission (6 vs 11 months, $P<0.001$ ) in the MTX and prednisone group. ${ }^{28}$ As for clinical remission, the observed rates were $55.5 \%$ upon GCs vs $32.8 \%$ in the control group $(P=0.0005)$ at 2 years in Svensson et al, ${ }^{25} 44.8 \%$ vs $27.8 \%$, respectively $(P=0.02)$ at 1 year in Montecucco et al, ${ }^{29}$ and $76.7 \%$ vs $33.3 \%$, respectively $(P=0.01)$ at 18 months in Todoerti et al. ${ }^{27}$ In the latter study, the time-adjusted probability of being in disease activity score (DAS) remission was significantly higher in the prednisone group at 1 year and 18 months. ${ }^{27}$ Of note, in Svensson et al, ${ }^{25}$ a significantly less worsening of radiographic damage was observed at 2 years among patients in remission compared to those without remission.

Some observations need to be pointed out: first, with regard to the COBRA study, the 5-year follow-up showed that the COBRA-treated group had a lower yearly damage progression than the sulfasalazine group despite similar disease activity levels, supporting the role of prednisolone as a disease-modifying drug. ${ }^{50}$ In this study, the experimental arm included also MTX, making it difficult to ascribe the beneficial effects only to prednisolone. However, it had been previously shown that the addition of MTX to sulfasalazine was not superior to sulfasalazine alone in reducing disease activity and structural changes over 5 years of follow-up. ${ }^{51}$ Finally, the stepdown strategy employed in the COBRA trial showed good efficacy and limited toxicity also in clinical practice. ${ }^{52}$ However, as treatment administered in the COBRA trial is not frequently prescribed in daily practice, den Uyl et al undertook a noninferiority trial to compare this regimen with the COBRA-light, ie, a lower dose of prednisolone tapered to $7.5 \mathrm{mg}$ /day over 9 rather than 6 weeks, and MTX but no sulfasalazine. ${ }^{53}$ At 6 months, results on disease activity as measured by DAS44 showed that the COBRA-light strategy was most likely to be noninferior to COBRA, with the possible advantage of less safety concerns. ${ }^{53}$ Recently, Verschueren et al randomized high-risk, early RA patients to receive either the COBRA classic scheme, the COBRA Slim (MTX +30 mg prednisone tapered to $5 \mathrm{mg}$ from week 6 ), or the COBRA Avant-Garde (replacing MTX in the COBRA Slim with leflunomide). ${ }^{54}$ The rates of clinical remission, good EULAR response, and health assessment questionnaire response at week 16 were similar among groups. Yet, the short-term safety profile was significantly better in the Slim patients, with a frequency of therapy-related AEs of $46.9 \%$ vs $61.2 \%$ in the COBRA Classic and $69.1 \%$ in the AvantGarde groups $(P=0.006) .{ }^{54}$ When the COBRA Slim regimen was compared to MTX monotherapy in low-risk early RA patients for 16 weeks, a higher, although not significant, rate of remission, good EULAR response, and health assessment questionnaire response were yielded, with significantly more COBRA Slim patients having a health assessment questionnaire score of $0(51.2 \%$ vs $23.4 \%, P=0.006) .{ }^{55}$

We intentionally excluded from Table 1 the studies from Kirwan, as not all patients received DMARDs, ${ }^{56}$ and from van Everdingen et al, as prednisone was given as monotherapy for at least the first 6 months. ${ }^{57}$ Nevertheless, the results from these studies deserve some attention. The first was a 2-year multicenter, randomized, placebo-controlled trial on the efficacy and safety of $7.5 \mathrm{mg}$ /day prednisolone in 128 patients with early RA (disease duration $<2$ years). ${ }^{56} \mathrm{~A}$ very little change-of-hand joint destruction, that persisted over time, was observed in the prednisolone group only, in which a significantly lower percentage of patients developed hand erosions after 1 and 2 years of treatment. However, 1 year after GC withdrawal, joint destruction resumed, although at a lesser extent in the prednisolone group compared to the placebo group. ${ }^{58}$ Also, except for a between-group comparable acute-phase response, the improvement of disability, joint inflammation, and pain was more rapid in the prednisolone group (starting from month 3), but it did not persist over time. ${ }^{56,58}$ 
The second study evaluated the effect of prednisone monotherapy in early RA patients (disease duration $<1$ year). They were randomized to $10 \mathrm{mg}$ prednisone $(\mathrm{n}=41)$ or placebo $(n=40)$ over a 2 -year period, and the use of sulfasalazine as a rescue medication was allowed only after 6 months. ${ }^{57}$ Clinical efficacy outcomes comprised the evaluation of symptoms, general well-being, disability, grip strength, and C-reactive protein level. Although the prednisone group displayed a higher overall improvement at 1 and 2 years, only grip strength and the 28-joint score for tenderness remained significantly different up to 2 years. Radiologic progression and the mean total number of affected joints per patient were significantly less in the prednisone group already at 1 year, and up to 2 years. ${ }^{57}$

Taken together, these results show that the early intervention with low-dose GCs in combination with DMARDs may effectively delay radiographic progression, reduce signs and symptoms, and induce higher rates of clinical remission compared to DMARD monotherapy. Notably, the observation that the development of erosions, clinical symptoms and, to some extent, acute-phase response can occur independently of each other after GC treatment has led to the assumption of the involvement of underlying distinct mechanisms. ${ }^{56}$

The 2013 update of 2010 EULAR recommendations for the management of RA with drugs ${ }^{59}$ advocates considering low-dose GCs ( $<7.5 \mathrm{mg}$ prednisone or equivalent per day) as part of the initial treatment strategy in combination with one or more DMARDs. However, due to the concerns still existing on their long-term safety, GCs should be administered for a maximum of 6 months and the dose tapered as soon as clinically feasible. In addition, their use as monotherapy should be limited only to patients in whom all other synthetic DMARDs have contraindications. ${ }^{57,59}$

Based on the conventional definition of a DMARD, which aims at improving long-term prognosis (ie, death and disabilities in RA ${ }^{60}$ GCs can likely be considered as such, at least in early RA.

\section{The HPA axis and circadian rhythm in RA: rationale for the use of $\mathrm{MR}$ prednisone}

During an inflammatory response, there is an interplay between the immune system and the HPA axis. Indeed, the increase of pro-inflammatory cytokines, such as IL-6, triggers the production of adrenocorticotropic hormone (ACTH) and cortisol, which, in turn, exerts negative feedback regulation on hypothalamus, anterior pituitary, and ongoing inflammation. ${ }^{16}$ Accordingly, in RA patients, the rise of IL-6 has been shown to precede, and positively correlate with, the increase of ACTH and cortisol. ${ }^{15,61-63}$ However, although RA patients display higher early morning serum levels of IL-6 than healthy subjects (Figure 2D), the levels of cortisol ${ }^{15}$ (Figure 2A) and $\mathrm{ACTH}^{61}$ are similar. This imbalance is likely to be responsible for the inadequate control of inflammation that leads to the occurrence of MS, which remains a critical issue in the management of RA patients due to their impact on QoL and productivity. In a survey conducted across eleven European countries, early RA patients suffering from impaired morning function at least thrice a week reported that their QoL, morning activities, emotional state, and job were significantly compromised by the impaired morning function; ${ }^{7} 18 \%$ of them were unable to work because of RA, and only a minority of subjects in working age were in paid employment. Also, impaired morning function was considered by $40 \%$ of working respondents to be the cause of time off work in the previous 6 months, with a mean of 4.5 working days lost per person. ${ }^{7}$ Recently, it has been reported that the prevalence of morning stiffness among RA patients in the US is $74.1 \%$, and that it has remained relatively unchanged from 2003 to 2014 despite the development of new agents. ${ }^{64}$ Severe and long-lasting morning stiffness in early RA has been shown to significantly increase the risk of early retirement within 3 years from disease onset, ${ }^{9}$ and to exert a stronger negative impact on patients' QoL, working ability (ie, tasks that patients were able to carry out), working life (eg, less working hours and career progression), and work performance (eg, frequent late arrival at work and sick leave).${ }^{10}$ Moreover, it has been estimated that the overall cost for RA-related morning stiffness is 27,712 Euros per patient per year, and, on average, $96 \%$ of the overall production losses depends on early retirement. ${ }^{11}$ Therefore, the implementation of therapeutic strategies capable of reducing MS especially in early RA patients, such as the addition of lowdose MR-prednisone to DMARDs, will have a strong impact on patients' QoL and relevant economic consequences.

The observation that RA symptoms change in a circadian fashion (Figure 1), resembling that of inflammatory cytokines, has led to the hypothesis that the timing of GC administration could affect the inflammatory process typical of RA and, consequently, the occurrence of MS. In patients with active RA, four administrations of low-dose (5.0-7.5 mg/day) prednisolone at $2 \mathrm{am}$ led to a significant improvement from baseline in morning stiffness, pain, and joint inflammation (Figure 3) ${ }^{30}$ However, the same dose taken at $7.30 \mathrm{am}$ induced a significant but less pronounced reduction of morning stiffness only (Figure 3 ). Also, both regimens significantly reduced the circulating levels of IL-6, 


\section{Time point of administration of prednisolone}
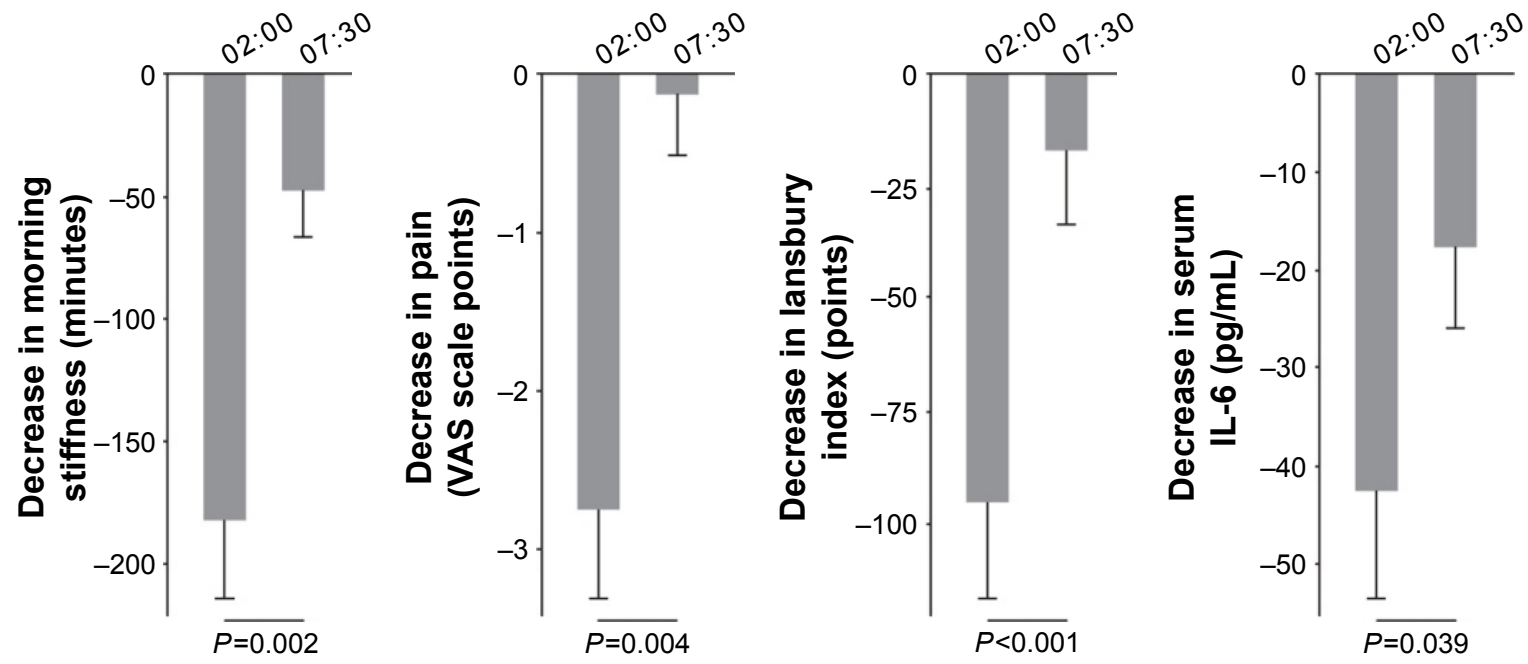

Figure 3 Reduction of clinical symptoms and serum interleukin-6 (IL-6) levels after nighttime (2 am) and morning (7.30 am) administration of 5.0-7.5 mg of prednisolone for five consecutive days in two groups of RA patients ( $n=13$ in each group).

Notes: Baseline characteristics of the two groups treated with prednisolone were similar. Values are expressed as the mean and standard error of mean decrease in each variable. Republished with permission of John Wiley and Sons Inc, from Straub RH, Cutolo M. Circadian rhythms in rheumatoid arthritis: implications for pathophysiology and therapeutic management. Arthritis Rheum. 2007;56(2):399-408; permission conveyed through Copyright Clearance Center, Inc. ${ }^{15}$

Abbreviations: RA, rheumatoid arthritis; VAS, visual analog scale.

but the extent of reduction was higher with nighttime administration (Figure 3).${ }^{30}$ As waking up patients may influence the activity of the HPA axis, the new formulation of MR prednisone has been developed, to release the drug in a delayed but programmed manner. MR prednisone is currently approved in the USA and several European countries, including Italy, for the treatment of adults with moderate-to-severe, active RA, particularly when accompanied by morning stiffness. Tablets $(1,2$, or $5 \mathrm{mg})$ are taken at bedtime after a meal, so that the gastric/intestinal fluids cause the inactive shell surrounding the prednisone core to open and the active drug to be released approximately 4 hours after food intake. In healthy subjects, $5 \mathrm{mg}$ MR-prednisone given at $8 \mathrm{pm}$ displayed a mean plasma concentration profile similar to that of $5 \mathrm{mg}$ immediate-release (IR) prednisone given at $2 \mathrm{am}$, but a significantly, programmed, delayed time (of approximately 4 hours) to maximum plasma levels (Figure 4). ${ }^{65}$

Therefore, while IR prednisone reached the maximum plasma concentration 2 hours after administration, it took approximately 6 to 6.5 hours for MR prednisone to reach the plasma peak. Also, the time to onset of absorption of MR prednisone was delayed by approximately 3.5 hours, but thereafter $>80 \%$ of the drug was released within 2 hours from tablet opening (Figure 4$).{ }^{65}$

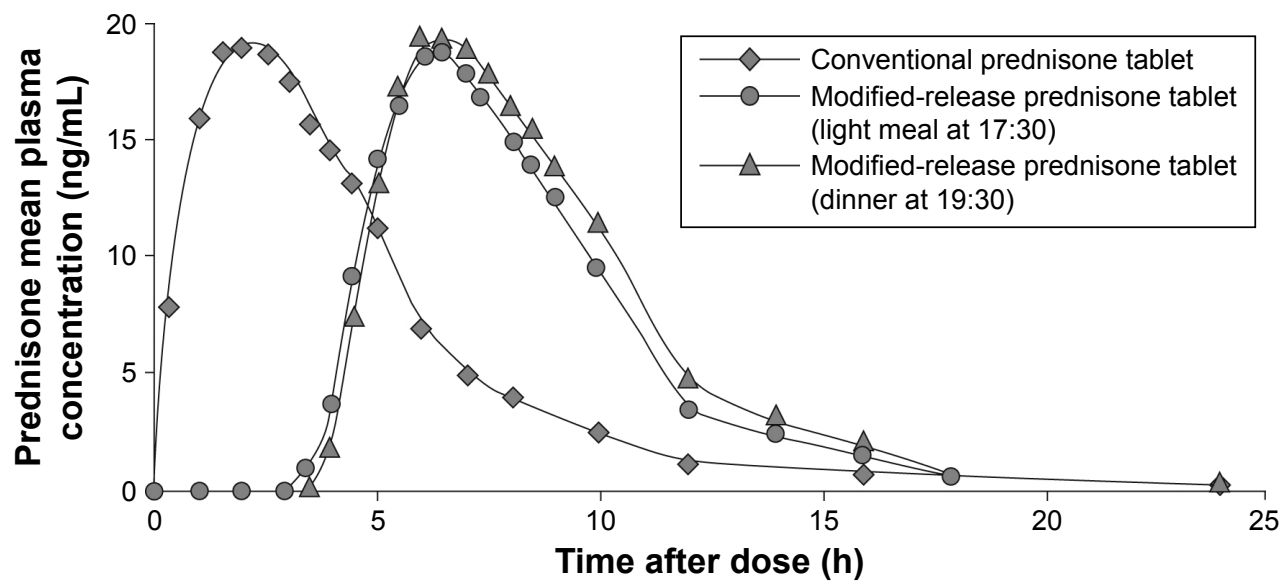

Figure 4 Pharmacokinetics of conventional and modified-release (MR) prednisone.

Notes: MR-prednisone was measured after a light meal at 17.30 or dinner at 19.30. Alten R. Chronotherapy with modified-release prednisone in patients with rheumatoid arthritis. Expert Review of Clinical Immunology. 2012;8(2):123-133, reprinted by permission of the publisher (Taylor \& Francis Ltd, http://www.tandfonline.com). ${ }^{81}$ Abbreviations: IL-6, interleukin-6; MR, modified-release; VAS, visual analog scale. 
In line with these results, when the plasma levels of prednisone were measured over 24 hours in nine RA patients given $5 \mathrm{mg}$ MR prednisone at bedtime (with or after a meal, as fasting reduces the bioavailability), a peak was observed within 4 to 6 hours from intake. ${ }^{65}$

In nine patients with active RA, MR prednisone taken at $10 \mathrm{pm}$ yielded a significant reduction in morning stiffness, pain, disease activity, and acute-phase response after 14 days. ${ }^{63}$ Moreover, the large nocturnal increase of serum IL-6 was suppressed, with the highest peak being $42.2 \mathrm{pg} / \mathrm{mL}$ at $8.30 \mathrm{am}$ before treatment and $21.3 \mathrm{pg} / \mathrm{mL}$ at $1.35 \mathrm{am}$ after treatment. Worth noting was the fact that changes in the mean 24-hour IL-6 levels positively correlated with changes in morning stiffness $(r=0.71, P<0.05){ }^{63}$

The efficacy of MR prednisone given at bedtime was compared to that of IR prednisone administered early in the morning in the circadian administration of prednisone in rheumatoid arthritis (CAPRA-1) trial, a 12-week, double-blind randomized controlled trial conducted in 288 RA patients on DMARD therapy. ${ }^{31}$ The addition of MR prednisone to DMARDs induced a rapid, significant, and sustained reduction in the duration of morning joint stiffness from baseline. At the end of the study, the mean change from baseline was significantly higher in the MR prednisone group than in the IR prednisone group $(-22.7 \%$ vs $-0.4 \%$, respectively, $P=0.045$; mean absolute reduction: 44 vs 23 minutes). The only other significant difference observed between treatments was the relative change of IL-6, which decreased by $28.6 \%$ upon MR prednisone, while it remained unchanged in the IR prednisone group (at week 12: $P=0.032$ ), suggesting an augmented antiinflammatory activity of the new formulation. ${ }^{31}$

At the end of the 12-week double-blind phase, 249/288 patients entered a 9-month open-label phase of therapy with MR prednisone. One hundred and twenty-nine patients continued treatment with the experimental formulation (MR/MR), and 120 switched to MR prednisone from previous IR prednisone (IR/MR) if no significant improvement had been attained. ${ }^{32}$ At the beginning of the open-label phase, the reduction of morning stiffness from baseline was equal to $-34.5 \%$ in the $\mathrm{MR} / \mathrm{MR}$ group vs $-1.4 \%$ in the IR/MR group. After 3 months, the mean change from baseline was $-56 \%$ in the MR/MR group and $-54 \%$ in the IR/MR. This reduction was sustained throughout the extension phase, being $-55 \%$ and $-45 \%$, respectively, at the end of 9 months. It is worth noting that at the end of the study, $17 \%$ of patients no longer reported morning stiffness, and $37 \%$ of the 219 patients who completed the 12 -month study achieved an ACR20 response. ${ }^{32}$ In addition, the 9-month evening intake of MR prednisone significantly improved IL-6 levels, pain, DAS28, and patients' and physicians' global assessment of disease activity both in the MR/MR and in the IR/MR group. ${ }^{32}$

In the subsequent CAPRA-2 trial, patients with active RA on DMARD therapy were randomized 2:1 to receive either $5 \mathrm{mg}$ MR prednisone $(\mathrm{n}=231)$ or placebo $(\mathrm{n}=119)$ for 12 weeks. ${ }^{33}$ The combination of low-dose MR prednisone and DMARDs provided a rapid (already at week 2) and significantly higher rate of ACR20 response, which was sustained throughout the study period (at week 12: $48 \%$ vs $29 \%$ in the placebo group, $P<0.001$ ). Similarly, at week 12 , $22 \%$ of patients in the MR prednisone group vs $10 \%$ in the placebo group attained an ACR50 response $(P<0.006)$. Upon MR prednisone, a greater improvement from baseline was observed at week 12 in the duration of morning stiffness ( $-55 \%$ in the MR prednisone group vs $-35 \%$ in the placebo group, $P<0.002$ ), pain, disease severity, fatigue, and physical function. ${ }^{33}$ Furthermore, in a clinical practice setting, MR prednisone given for 9 months to RA patients has been shown to significantly improve patients' functional ability. ${ }^{66}$

Overall, the encouraging results reported here support the rapid benefit provided by low-dose MR prednisone in combination with DMARDs in relieving RA symptoms and improving morning function also in subjects who had switched to MR prednisone after inadequately responding to the conventional formulation. ${ }^{31,32,67}$ However, the long-term efficacy and safety of MR prednisone need further investigation, especially in the real-world setting, and in patients with early RA, in which the administration of MR prednisone may likely provide even better results than those observed in patients with established disease.

One concern on the use of GCs is regarding the possible suppression of the HPA axis, as this is considered the cause of virtually all known AEs associated with the administration of GCs. In fact, dose-dependent adrenal insufficiency is common in patients treated with long-term GC therapy as a result of negative-feedback mechanism leading to adrenal suppression. ${ }^{16,68,69}$ Interestingly, assessment of the plasma cortisol response to ACTH injection in RA patients before and after 12 weeks of treatment with low-dose prednisolone $(7.5 \mathrm{mg} /$ day) unveiled a $35 \%$ reduction in the mean values of plasma cortisol levels at 60 minutes in the prednisolone group but not in the placebo group..$^{70}$ Also, although the HPA axis response in individual patients was in the normal range, $46 \%$ of prednisolone-treated patients failed to reach the normal maximum cortisol response to ACTH, suggesting a suppressing effect of low-dose GC 
on adrenal function. ${ }^{70}$ However, cortisol level examination in eleven female RA patients before and after ACTH administration unveiled higher levels at baseline, compared to ten matched healthy controls, but decreased secretion in response to ACTH, suggesting a subtle HPA hypofunction at the adrenocortical level, independent of GC administration. ${ }^{71}$ Besides GC therapy dosage and duration, it is still debated whether the timing of administration and the number of doses given may affect adrenal function. In the study from Kirwan et al conducted in nine RA patients treated with MR prednisone for 14 days, ${ }^{63}$ the early morning cortisol peak concentration increased from $14.1 \mu \mathrm{g} / \mathrm{dL}$ to $19.4 \mu \mathrm{g} / \mathrm{dL}$. These data, together with the results on IL-6 plasma peak support a change in the interaction between the HPA axis and immune system in favor of HPA preservation (and even activation) upon MR prednisone. ${ }^{63}$ Actually, no signs or symptoms of HPA axis suppression were observed in the extension phase of the CAPRA-1 trial ${ }^{32}$ and, when the HPA axis function was tested in a subset of 28 patients from the same trial, no change in the mean plasma cortisol response to corticotropin-releasing hormone stimulation test, or in the proportion of responders was observed over time, regardless of the switch from IR to MR prednisone occurring in the open-label phase. ${ }^{35}$

Collectively, these studies show that the adherence to the circadian night GC production together with the protection of the HPA axis allows the use of low-dose MR prednisone chronotherapy as a tailored approach to optimize therapy.

\section{Safety of GCs and MR prednisone}

It is well established that the toxicities experienced by GC-treated patients depend on the duration and dosage of therapy. ${ }^{72-76}$ The analysis of data on self-reported health problems from unselected RA patients in routine practice showed that the frequency of AEs increased with the dose of GCs according to two distinct patterns. ${ }^{77}$ Indeed, a "linear" dependence was found between the rate of cushingoid phenotype, ecchymosis, leg edema, mycosis, parchment-like skin, shortness of breath, and sleep disturbance and the dose received. Also, a "threshold" pattern was identified, describing an elevated frequency of events beyond a certain threshold of GC dosage. Accordingly, doses $>7.5 \mathrm{mg} /$ day were found to be associated with glaucoma, depression/ listlessness, and increased blood pressure, doses $\geq 5 \mathrm{mg} /$ day with epistaxis and weight gain, and doses $<5 \mathrm{mg}$ /day with eye cataract. ${ }^{77}$

A recent systematic review reported that some of the events associated with the use of high-dose GCs, including weight gain, hyperglycemia and diabetes, elevated blood pressure, hypertension, increased risk of fractures and infections, cognitive dysfunction, and cataract may occur also with low doses. ${ }^{73}$ However, to date, high-quality evidence on the toxicity of low-dose GCs is scarce. A comprehensive review of data from RCTs failed to identify relevant toxicities associated with doses of up to $10 \mathrm{mg}$ of prednisone equivalent/day given for up to 2 years to RA patients, and the safety profile of prednisone was found to be similar to that of placebo. ${ }^{78}$ In addition, low-dose GCs ( $<8.5 \mathrm{mg} /$ day prednisone or equivalent) were shown not to impair glucose metabolism in premenopausal RA patients without other risk factors. ${ }^{79}$ Moreover, a recent systematic review on the efficacy of GCs in early RA concluded that no new safety concerns surfaced over 2 years beyond those previously reported. ${ }^{22}$

By changing the timing of administration, however, it is possible to increase the benefit/risk ratio of GC therapy, as corroborated by the results from the CAPRA studies. ${ }^{31,33}$ Indeed, the safety analysis showed an overall similar frequency of AEs occurred during treatment with MR prednisone, IR prednisone ( $41 \%$ in each group $\left.{ }^{31}\right)$, and placebo (42.9\% in the MR prednisone group vs $48.7 \%$ in the placebo group $\left.^{33}\right)$. The most frequent AE was RA worsening, observed in $8 \%$ and $9 \%$ of patients in Buttgereit et al, ${ }^{31}$ and in $6.5 \%$ and 9.2\% in Buttgereit et al. ${ }^{33}$ As shown in Table 2, summarizing the results from the integrated analysis of the AEs occurring with a frequency $\geq 2 \%$ in the CAPRA studies, ${ }^{31,33}$ no clinically relevant differences were observed among treatment groups after 12 weeks of therapy.

Even the frequency of AEs judged as treatment-related was comparable, being $13 \%, 11 \%,{ }^{31} 7.8 \%$, and $8.4 \%,{ }^{33}$ respectively. Premature discontinuation was reported in $8 \%$ of patients treated with MR prednisone and in 7\% with IR prednisone in Buttgereit et al, ${ }^{31}$ the most frequent reason being RA flare, and in $2.2 \%$ of cases treated with MR prednisone $(n=1$ in each case of headache, headache and hypertension, RA flare, glaucoma, and vomiting) and $0.8 \%$ with placebo (one case of headache) in Buttgereit et al. ${ }^{33}$ Only one of the serious AEs reported $(n=4[3 \%]$ and $3[2 \%]$ in Buttgereit et $\mathrm{al}^{31}$ and $\mathrm{n}=1[0.4 \%]$ and $2[1.7 \%]$ in Buttgereit et $\mathrm{al}^{33}$ ) was considered to be treatment-related (in one patient given IR prednisone $^{31}$ ), whereas the only death occurred (in the IR prednisone group ${ }^{31}$ ) was judged as therapy-unrelated. In line with these results, during the 9-month open label phase of the CAPRA-1 study, $51 \%$ of patients reported AEs and $4.8 \%$ discontinued treatment for safety reasons, the most frequent being RA exacerbation. ${ }^{32}$ 
Table 2 Integrated analysis of adverse events occurring in $\geq 2 \%$ of patients with rheumatoid arthritis, after 12 weeks of therapy with placebo, MR prednisone, or IR prednisone ( $\leq 5 \mathrm{mg} / \mathrm{d} \mathrm{vs}>5 \mathrm{mg} / \mathrm{d})$ in the CAPRA studies

\begin{tabular}{|c|c|c|c|c|c|c|c|}
\hline \multirow[t]{2}{*}{ Parameter } & \multirow{2}{*}{$\frac{\text { Placebo }}{N=119}$} & \multicolumn{3}{|c|}{ MR prednisone } & \multicolumn{3}{|c|}{ Conventional IR prednisone } \\
\hline & & $\begin{array}{l}\leq 5 \mathrm{mg} / \mathrm{d} \\
\mathrm{N}=313\end{array}$ & $\begin{array}{l}>5 \mathrm{mg} / \mathrm{d} \\
\mathrm{N}=62\end{array}$ & $\begin{array}{l}\text { Total } \\
N=375\end{array}$ & $\begin{array}{l}\leq 5 \mathrm{mg} / \mathrm{d} \\
\mathrm{N}=76\end{array}$ & $\begin{array}{l}>5 \mathrm{mg} / \mathrm{d} \\
\mathrm{N}=68\end{array}$ & $\begin{array}{l}\text { Total } \\
N=\mid 44\end{array}$ \\
\hline Daily dose, $\mathrm{mg}$ (mean $\pm \mathrm{SD})$ & NA & $4.86 \pm 0.37$ & $8.45 \pm 1.49$ & $5.46 \pm 1.50$ & $4.93 \pm 0.34$ & $8.59 \pm 1.48$ & $6.66 \pm 2.11$ \\
\hline Any adverse event, \% & 48.7 & 43.1 & 35.5 & 41.9 & 42.1 & 36.8 & 39.6 \\
\hline \multicolumn{8}{|l|}{ Severity, \% } \\
\hline Mild & 29.4 & 20.4 & 8.1 & 18.4 & 18.4 & 16.2 & 17.4 \\
\hline Moderate & I5.I & 20.8 & 22.6 & 21.1 & 19.7 & 19.1 & 19.4 \\
\hline Severe & 4.2 & 1.9 & 4.8 & 2.4 & 3.9 & 1.5 & 2.8 \\
\hline \multicolumn{8}{|l|}{ Preferred term, \% } \\
\hline \multicolumn{8}{|l|}{ Gastrointestinal disorders } \\
\hline Abdominal pain (upper) & 1.7 & 1.6 & 1.6 & 1.6 & 7.9 & 2.9 & 5.6 \\
\hline Diarrhea & 0.8 & 1.3 & 0 & 1.1 & 2.6 & 2.9 & 2.8 \\
\hline Nausea & 0 & 2.2 & 1.6 & 2.1 & 2.6 & 2.9 & 2.8 \\
\hline Dyspepsia & 0 & 0.6 & 1.6 & 0.8 & 0 & 4.4 & 2.1 \\
\hline \multicolumn{8}{|l|}{ Infections and infestations } \\
\hline Nasopharyngitis & 3.4 & 4.8 & 1.6 & 4.3 & 6.6 & 4.4 & 5.6 \\
\hline Bronchitis & 4.2 & 1.0 & 3.2 & 1.3 & 3.9 & 2.9 & 3.5 \\
\hline URTI & 0.8 & 0.6 & 0 & 0.5 & 0 & 4.4 & 2.1 \\
\hline \multicolumn{8}{|c|}{ Musculoskeletal and connective tissue disorders } \\
\hline Aggravated RA/RA flare & 26.1 & 14.4 & 4.8 & $12.8^{\mathrm{a}}$ & 11.8 & 7.4 & 9.7 \\
\hline \multicolumn{8}{|l|}{ Ear and labyrinth disorders } \\
\hline Vertigo & 0 & 1.3 & 0 & 1.1 & 3.9 & 2.9 & 3.5 \\
\hline \multicolumn{8}{|l|}{ Nervous system disorders } \\
\hline Headache & 4.2 & 4.5 & 1.6 & 4.0 & 3.9 & 2.0 & 3.5 \\
\hline \multicolumn{8}{|c|}{ General disorders and administration-site conditions } \\
\hline Chest pain & 0 & 0.3 & 1.6 & 0.5 & 2.6 & 1.5 & 2.1 \\
\hline
\end{tabular}

Notes: ${ }^{\mathrm{P}}=0.0137$ between the placebo and the MR-prednisone groups. All other comparisons are not significant. Republished with permission of John Wiley and Sons Inc, from Buttgereit F, Szechinski J, Doering G, et al. Integrated safety summary of modified-release prednisone and immediate-release prednisone comparing doses $<5$ mg/day versus $>5 \mathrm{mg} /$ day. Arthritis and Rheumatism. 20I I;63(I):S475; permission conveyed through Copyright Clearance Center, Inc. ${ }^{82}$

Abbreviations: CAPRA, circadian administration of prednisone in rheumatoid arthritis; IR, immediate-release; MR, modified-release; NA, not applicable; RA, rheumatoid arthritis; SD, standard deviation; URTI, upper respiratory tract infection.

As for the effects of MR prednisone on the activity of HPA axis, the main results have been reported in the previous section of this review.

Overall, the data collected thus far on the use of MR prednisone point toward a favorable safety profile of this formulation, further sustaining its implementation in the management of RA patients to optimize the benefit/risk ratio of GC therapy. Moreover, these data provide evidence that toxicities occurring in GC-treated patients depend on the steroid backbone of GCs rather than on the specific features of the individual formulations (ie, IR vs MR).

\section{Summary}

A large body of evidence supports prompt intervention, in early RA patients, with low-dose GCs in combination with DMARDs as an effective and safe option to delay radiographic progression, reduce signs and symptoms, and induce high rates of clinical remission. Accordingly, their use has been recommended by EULAR as part of the initial treatment strategy in RA patients, although for no more than 6 months.
In established RA, in which the management of MS remains challenging, chronotherapy with low-dose MR prednisone is emerging as a feasible approach to optimize the benefit/risk ratio of GC therapy, by targeting the interplay between the immune system and HPA axis without impacting the adrenal function, but possibly even stimulating it.

\section{Future perspectives}

Further studies assessing the efficacy and safety of low-dose GCs in the long-term and real-world setting of early RA are warranted, to assess whether their use could be prolonged beyond 6 months, as currently recommended by EULAR.

Despite the encouraging results on the efficacy and safety of chronotherapy with MR prednisone in RA patients, it is of utmost importance to conduct studies in large populations of patients with established RA as well as early disease, with long follow-up periods and under clinical practice conditions. Moreover, further efforts for improving the administration of GCs are needed to preserve the HPA axis function. In this regard, the development of new formulations is ongoing, such 
as liposomes filled with GCs. ${ }^{80}$ This approach has translated into targeted delivery of GC with a high benefit/risk ratio. Encouraging, preliminary results regarding the efficacy and tolerability of liposomal GCs have been obtained in in vivo models of arthritis and in 16 RA patients included in a Phase I trial, but we are still awaiting further evidence. ${ }^{80}$ Finally, results are awaited from trials testing MR prednisone in other rheumatic and nonrheumatic diseases characterized by severe inflammatory early MS (eg, polymyalgia rheumatica [ClinicalTrials.gov Identifier: NCT01821040] and nocturnal asthma [ClinicalTrials.gov Identifier of an explorative study to collect data for a subsequent controlled trial: NCT00686335]).

\section{Method of literature search}

PubMed database was searched in December 2015 starting with the following keywords: "rheumatoid arthritis" AND "glucocorticoid" AND ("low-dose prednisone" OR "modified-release prednisone"). The search retrieved approximately 70 results. Studies were excluded that were not published in English, in addition to hand-selected case studies, abstracts, letters, and reviews. Additionally, more specific searches regarding the mechanism of action of GCs and treatment of early RA were carried out.

\section{Disclosure}

The authors report no conflicts of interest in this work.

\section{References}

1. Shetty A, Hanson R, Korsten P, et al. Tocilizumab in the treatment of rheumatoid arthritis and beyond. Drug Des Devel Ther. 2014;8: 349-364.

2. Zampeli E, Vlachoyiannopoulos PG, Tzioufas AG. Treatment of rheumatoid arthritis: unraveling the conundrum. J Autoimmun. 2015; $65: 1-18$.

3. Backman CL. Employment and work disability in rheumatoid arthritis. Curr Opin Rheumatol. 2004;16(2):148-152.

4. Sokka T. Work disability in early rheumatoid arthritis. Clin Exp Rheumatol. 2003;21(5 Suppl 31):S71-S74.

5. Kojima M, Kojima T, Ishiguro N, et al. Psychosocial factors, disease status, and quality of life in patients with rheumatoid arthritis. $J$ Psychosom Res. 2009;67(5):425-431.

6. Cutolo M, Kitas GD, van Riel PL. Burden of disease in treated rheumatoid arthritis patients: going beyond the joint. Semin Arthritis Rheum. 2014;43(4):479-488.

7. da Silva JA, Phillips S, Buttgereit F. Impact of impaired morning function on the lives and well-being of patients with rheumatoid arthritis. Scand J Rheumatol Suppl. 2011;125:6-11.

8. Yazici Y, Pincus T, Kautiainen H, Sokka T. Morning stiffness in patients with early rheumatoid arthritis is associated more strongly with functional disability than with joint swelling and erythrocyte sedimentation rate. J Rheumatol. 2004;31(9):1723-1726.

9. Westhoff G, Buttgereit F, Gromnica-Ihle E, Zink A. Morning stiffness and its influence on early retirement in patients with recent onset rheumatoid arthritis. Rheumatology (Oxford). 2008;47(7):980-984.

10. Mattila K, Buttgereit F, Tuominen R. Impact of morning stiffness on working behaviour and performance in people with rheumatoid arthritis. Rheumatol Int. 2014;34(12):1751-1758.
11. Mattila K, Buttgereit F, Tuominen R. Influence of rheumatoid arthritisrelated morning stiffness on productivity at work: results from a survey in 11 European countries. Rheumatol Int. 2015;35(11):1791-1797.

12. Kowanko IC, Pownall R, Knapp MS, Swannell AJ, Mahoney PG. Circadian variations in the signs and symptoms of rheumatoid arthritis and in the therapeutic effectiveness of flurbiprofen at different times of day. Br J Clin Pharmacol. 1981;11(5):477-484.

13. Harkness JA, Richter MB, Panayi GS, et al. Circadian variation in disease activity in rheumatoid arthritis. Br Med J Clin Res Ed. 1982; 284(6315):551-554.

14. Bellamy N, Sothern RB, Campbell J, Buchanan WW. Circadian rhythm in pain, stiffness, and manual dexterity in rheumatoid arthritis: relation between discomfort and disability. Ann Rheum Dis. 1991; 50(4):243-248.

15. Straub RH, Cutolo M. Circadian rhythms in rheumatoid arthritis: implications for pathophysiology and therapeutic management. Arthritis Rheum. 2007;56(2):399-408.

16. Spies CM, Straub RH, Cutolo M, Buttgereit F. Circadian rhythms in rheumatology - a glucocorticoid perspective. Arthritis Res Ther. 2014; 16 Suppl 2:S3.

17. Nicolaides NC, Charmandari E, Chrousos GP, Kino T. Circadian endocrine rhythms: the hypothalamic-pituitary-adrenal axis and its actions. Ann N Y Acad Sci. 2014;1318:71-80.

18. Hench PS. Potential reversibility of rheumatoid arthritis. Ann Rheum Dis. 1949;8(2):90-96.

19. Hench PS, Kendall EC. The effect of a hormone of the adrenal cortex (17-hydroxy-11-dehydrocorticosterone; compound E) and of pituitary adrenocorticotropic hormone on rheumatoid arthritis. Proc Staff Meet Mayo Clin. 1949;24(8):181-197.

20. Da Silva JA, Bijlsma JW. Optimizing glucocorticoid therapy in rheumatoid arthritis. Rheum Dis Clin North Am. 2000;26(4):859-880.

21. Pincus T, Sokka T, Cutolo M. The past versus the present, 1980-2004: reduction of mean initial low-dose, long-term glucocorticoid therapy in rheumatoid arthritis from 10.3 to $3.6 \mathrm{mg}$ /day, concomitant with early methotrexate, with long-term effectiveness and safety of less than $5 \mathrm{mg}$ /day. Neuroimmunomodulation. 2015;22(1-2):89-103.

22. Gaujoux-Viala C, Nam J, Ramiro S, et al. Efficacy of conventional synthetic disease-modifying antirheumatic drugs, glucocorticoids and tofacitinib: a systematic literature review informing the 2013 update of the EULAR recommendations for management of rheumatoid arthritis. Ann Rheum Dis. 2014;73(3):510-515.

23. Pincus T, Cutolo M. Clinical trials documenting the efficacy of lowdose glucocorticoids in rheumatoid arthritis. Neuroimmunomodulation. 2015;22(1-2):46-50.

24. Boers M, Verhoeven AC, Markusse HM, et al. Randomised comparison of combined step-down prednisolone, methotrexate and sulphasalazine with sulphasalazine alone in early rheumatoid arthritis. Lancet. 1997;350(9074):309-318.

25. Svensson B, Boonen A, Albertsson K, van der Heijde D, Keller C, Hafström I. Low-dose prednisolone in addition to the initial diseasemodifying antirheumatic drug in patients with early active rheumatoid arthritis reduces joint destruction and increases the remission rate: a two-year randomized trial. Arthritis Rheum. 2005;52(11):3360-3370.

26. Wassenberg S, Rau R, Steinfeld P, Zeidler H. Very low-dose prednisolone in early rheumatoid arthritis retards radiographic progression over two years: a multicenter, double-blind, placebo-controlled trial. Arthritis Rheum. 2005;52(11):3371-3380.

27. Todoerti M, Scirè CA, Boffini N, Bugatti S, Montecucco C, Caporali R. Early disease control by low-dose prednisone comedication may affect the quality of remission in patients with early rheumatoid arthritis. Ann N Y Acad Sci. 2010;1193:139-145.

28. Bakker MF, Jacobs JWG, Welsing PMJ, et al. Low-dose prednisone inclusion in a methotrexate-based, tight control strategy for early rheumatoid arthritis: a randomized trial. Ann Intern Med. 2012;156(5):329-339.

29. Montecucco C, Todoerti M, Sakellariou G, Scirè CA, Caporali R. Lowdose oral prednisone improves clinical and ultrasonographic remission rates in early rheumatoid arthritis: results of a 12-month open-label randomised study. Arthritis Res Ther. 2012;14(3):R112. 
30. Arvidson NG, Gudbjörnsson B, Larsson A, Hällgren R. The timing of glucocorticoid administration in rheumatoid arthritis. Ann Rheum Dis. 1997;56(1):27-31.

31. Buttgereit F, Doering G, Schaeffler A, et al. Efficacy of modified-release versus standard prednisone to reduce duration of morning stiffness of the joints in rheumatoid arthritis (CAPRA-1): a double-blind, randomised controlled trial. Lancet. 2008;371(9608):205-214.

32. Buttgereit F, Doering G, Schaeffler A, et al. Targeting pathophysiological rhythms: prednisone chronotherapy shows sustained efficacy in rheumatoid arthritis. Ann Rheum Dis. 2010;69(7):1275-1280.

33. Buttgereit F, Mehta D, Kirwan J, et al. Low-dose prednisone chronotherapy for rheumatoid arthritis: a randomised clinical trial (CAPRA-2). Ann Rheum Dis. 2013;72(2):204-210.

34. Cassidy J, Clarke S, Díaz-Rubio E, et al. Randomized phase III study of capecitabine plus oxaliplatin compared with fluorouracil/folinic acid plus oxaliplatin as first-line therapy for metastatic colorectal cancer. J Clin Oncol. 2008;26(12):2006-2012.

35. Alten R, Döring G, Cutolo M, et al. Hypothalamus-pituitary-adrenal axis function in patients with rheumatoid arthritis treated with nighttimerelease prednisone. J Rheumatol. 2010;37(10):2025-2031.

36. Alten R, Grahn A, Holt RJ, Rice P, Buttgereit F. Delayed-release prednisone improves fatigue and health-related quality of life: findings from the CAPRA-2 double-blind randomised study in rheumatoid arthritis. RMD Open. 2015;1(1):e000134.

37. Clarke LL, Jessop DS, Hunt LP, Straub RH, Perry MG, Kirwan JR. Alleviation of morning joint stiffness by low-dose prednisone in rheumatoid arthritis is associated with circadian changes in IL-6 and cortisol. Int J Clin Rheumatol. 2011;6(2):241-249.

38. Nader N, Chrousos GP, Kino T. Circadian rhythm transcription factor CLOCK regulates the transcriptional activity of the glucocorticoid receptor by acetylating its hinge region lysine cluster: potential physiological implications. FASEB J. 2009;23(5):1572-1583.

39. Charmandari E, Chrousos GP, Lambrou GI, et al. Peripheral CLOCK regulates target-tissue glucocorticoid receptor transcriptional activity in a circadian fashion in man. PLoS One. 2011;6(9):e25612.

40. Aletaha D, Funovits J, Keystone EC, Smolen JS. Disease activity early in the course of treatment predicts response to therapy after one year in rheumatoid arthritis patients. Arthritis Rheum. 2007;56(10): 3226-3235.

41. Schipper LG, Fransen J, den Broeder AA, Van Riel PL. Time to achieve remission determines time to be in remission. Arthritis Res Ther. 2010;12(3):R97.

42. Bykerk VP, Keystone EC, Kuriya B, Larché M, Thorne JC, Haraoui B. Achieving remission in clinical practice: lessons from clinical trial data. Clin Exp Rheumatol. 2013;31(4):621-632.

43. Monti S, Montecucco C, Bugatti S, Caporali R. Rheumatoid arthritis treatment: the earlier the better to prevent joint damage. RMD Open. 2015;1(Suppl 1):e000057.

44. Aletaha D, Alasti F, Smolen JS. Optimisation of a treat-to-target approach in rheumatoid arthritis: strategies for the 3-month time point. Ann Rheum Dis. 2016;75(8):1479-1485.

45. Smolen JS, Aletaha D, Bijlsma JW, et al. Treating rheumatoid arthritis to target: recommendations of an international task force. Ann Rheum Dis. 2010;69(4):631-637.

46. Smolen JS, Breedveld FC, Burmester GR, et al. Treating rheumatoid arthritis to target: 2014 update of the recommendations of an international task force. Ann Rheum Dis. 2016;75(1):3-15.

47. Galloway JB, Hyrich KL, Mercer LK, et al. Anti-TNF therapy is associated with an increased risk of serious infections in patients with rheumatoid arthritis especially in the first 6 months of treatment: updated results from the British Society for Rheumatology Biologics Register with special emphasis on risks in the elderly. Rheumatology (Oxford). 2011;50(1):124-131.

48. Marchesoni A, Zaccara E, Gorla R, et al. TNF-alpha antagonist survival rate in a cohort of rheumatoid arthritis patients observed under conditions of standard clinical practice. Ann N Y Acad Sci. 2009;1173: 837-846.
49. Hansen M, Podenphant J, Florescu A, et al. A randomised trial of differentiated prednisolone treatment in active rheumatoid arthritis. Clinical benefits and skeletal side effects. Ann Rheum Dis. 1999; 58(11):713-718.

50. Landewé RBM, Boers M, Verhoeven AC, et al. COBRA combination therapy in patients with early rheumatoid arthritis: long-term structural benefits of a brief intervention. Arthritis Rheum. 2002;46(2): 347-356.

51. Maillefert JF, Combe B, Goupille P, Cantagrel A, Dougados M. Long term structural effects of combination therapy in patients with early rheumatoid arthritis: five year follow up of a prospective double blind controlled study. Ann Rheum Dis. 2003;62(8):764-766.

52. Verschueren P, Esselens G, Westhovens R. Daily practice effectiveness of a step-down treatment in comparison with a tight step-up for early rheumatoid arthritis. Rheumatology (Oxford). 2008;47(1):59-64.

53. den Uyl D, ter Wee M, Boers M, et al. A non-inferiority trial of an attenuated combination strategy ('COBRA-light') compared to the original COBRA strategy: clinical results after 26 weeks. Ann Rheum Dis. 2014;73(6):1071-1078.

54. Verschueren P, De Cock D, Corluy L, et al. Methotrexate in combination with other DMARDs is not superior to methotrexate alone for remission induction with moderate-to-high-dose glucocorticoid bridging in early rheumatoid arthritis after 16 weeks of treatment: the CareRA trial. Ann Rheum Dis. 2015;74(1):27-34.

55. Verschueren P, De Cock D, Corluy L, et al. Patients lacking classical poor prognostic markers might also benefit from a step-down glucocorticoid bridging scheme in early rheumatoid arthritis: week 16 results from the randomized multicenter CareRA trial. Arthritis Res Ther. 2015;17:97.

56. Kirwan JR. The effect of glucocorticoids on joint destruction in rheumatoid arthritis. The arthritis and rheumatism council low-dose glucocorticoid study group. $N$ Engl J Med. 1995;333(3):142-146.

57. van Everdingen AA, Jacobs JW, Siewertsz Van Reesema DR, Bijlsma JW. Low-dose prednisone therapy for patients with early active rheumatoid arthritis: clinical efficacy, disease-modifying properties, and side effects: a randomized, double-blind, placebo-controlled clinical trial. Ann Intern Med. 2002;136(1):1-12.

58. Hickling P, Jacoby RK, Kirwan JR. Joint destruction after glucocorticoids are withdrawn in early rheumatoid arthritis. Arthritis and rheumatism council low dose glucocorticoid study group. Br J Rheumatol. 1998;37(9):930-936.

59. Smolen JS, Landewé R, Breedveld FC, et al. EULAR recommendations for the management of rheumatoid arthritis with synthetic and biological disease-modifying antirheumatic drugs: 2013 update. Ann Rheum Dis. 2014;73(3):492-509.

60. Bijlsma JW. Disease control with glucocorticoid therapy in rheumatoid arthritis. Rheumatology (Oxford). 2012;51 Suppl 4:iv9-iv13.

61. Crofford LJ, Kalogeras KT, Mastorakos G, et al. Circadian relationships between interleukin (IL)-6 and hypothalamic-pituitary-adrenal axis hormones: failure of IL-6 to cause sustained hypercortisolism in patients with early untreated rheumatoid arthritis. $J$ Clin Endocrinol Metab. 1997;82(4):1279-1283.

62. Perry MG, Kirwan JR, Jessop DS, Hunt LP. Overnight variations in cortisol, interleukin 6, tumour necrosis factor alpha and other cytokines in people with rheumatoid arthritis. Ann Rheum Dis. 2009;68(1):63-68.

63. Kirwan JR, Clarke L, Hunt LP, Perry MG, Straub RH, Jessop DS. Effect of novel therapeutic glucocorticoids on circadian rhythms of hormones and cytokines in rheumatoid arthritis. Ann N Y Acad Sci. 2010;1193: $127-133$.

64. Prevalence of Morning Stiffness in a US Registry Population of Rheumatoid Arthritis Patients. ACR Meet Abstr. Available from: http://acrabstracts.org/abstract/prevalence-of-morning-stiffness-ina-us-registry-population-of-rheumatoid-arthritis-patients/. Accessed February 12, 2016.

65. Derendorf H, Ruebsamen K, Clarke L, Schaeffler A, Kirwan JR. Pharmacokinetics of modified-release prednisone tablets in healthy subjects and patients with rheumatoid arthritis. J Clin Pharmacol. 2013;53(3):326-333. 
66. Pfeiffer BM, Krenzer S, Dockhorn R, et al. Impact of modified-release prednisone on functional ability in patients with rheumatoid arthritis. Rheumatol Int. 2013;33(6):1447-1454.

67. Alten R, Holt R, Grahn A, et al. Morning stiffness response with delayed-release prednisone after ineffective course of immediate-release prednisone. Scand J Rheumatol. 2015;44(5):354-358.

68. Charmandari E, Nicolaides NC, Chrousos GP. Adrenal insufficiency. Lancet. 2014;383(9935):2152-2167.

69. Woods CP, Argese N, Chapman M, et al. Adrenal suppression in patients taking inhaled glucocorticoids is highly prevalent and management can be guided by morning cortisol. Eur J Endocrinol. 2015; 173(5):633-642.

70. Kirwan JR, Hickey SH, Hällgren R, et al. The effect of therapeutic glucocorticoids on the adrenal response in a randomized controlled trial in patients with rheumatoid arthritis. Arthritis Rheum. 2006;54(5): 1415-1421.

71. Radikova Z, Rovensky J, Vlcek M, et al. Adrenocortical response to low-dose ACTH test in female patients with rheumatoid arthritis. Ann N Y Acad Sci. 2008;1148:562-566.

72. Strehl C, Buttgereit F. Optimized glucocorticoid therapy: teaching old drugs new tricks. Mol Cell Endocrinol. 2013;380(1-2):32-40.

73. Kavanaugh A, Wells AF. Benefits and risks of low-dose glucocorticoid treatment in the patient with rheumatoid arthritis. Rheumatology (Oxford). 2014;53(10):1742-1751.

74. van der Goes MC, Jacobs JW, Bijlsma JW. The value of glucocorticoid co-therapy in different rheumatic diseases - positive and adverse effects. Arthritis Res Ther. 2014;16 Suppl 2:S2.
75. Alten R, Wiebe E. Hypothalamic-pituitary-adrenal axis function in patients with rheumatoid arthritis treated with different glucocorticoid approaches. Neuroimmunomodulation. 2015;22(1-2):83-88.

76. Santiago T, Jacobs JW, Saag KG, Buttgereit F, Pereira da Silva JA. Balancing the benefits and risks of low-dose glucocorticoid in rheumatoid arthritis. Acta Reumatol Port. 2015;40(1):10-22.

77. Huscher D, Thiele K, Gromnica-Ihle E, et al. Dose-related patterns of glucocorticoid-induced side effects. Ann Rheum Dis. 2009;68(7): 1119-1124.

78. Santiago T, da Silva JA. Safety of glucocorticoids in rheumatoid arthritis: evidence from recent clinical trials. Neuroimmunomodulation. 2015;22(1-2):57-65.

79. Penesová A, Rádiková Z, Vlček M, et al. Chronic inflammation and lowdose glucocorticoid effects on glucose metabolism in premenopausal females with rheumatoid arthritis free of conventional metabolic risk factors. Physiol Res. 2013;62(1):75-83.

80. Buttgereit F, Spies CM, Bijlsma JW. Novel glucocorticoids: where are we now and where do we want to go? Clin Exp Rheumatol. 2015; 33(4 Supp1 92):S29-S33.

81. Alten R. Chronotherapy with modified-release prednisone in patients with rheumatoid arthritis. Expert Rev Clin Immunol. 2012;8(2): 123-133.

82. Buttgereit F, Szechinski J, Doering G, et al. Integrated safety summary of modified-release prednisone and immediate-release prednisone comparing doses $<5 \mathrm{mg} /$ day versus $>5 \mathrm{mg}$ /day. Arthritis and Rheumatism. 2011;63(1):S475.
Therapeutics and Clinical Risk Management

\section{Publish your work in this journal}

Therapeutics and Clinical Risk Management is an international, peerreviewed journal of clinical therapeutics and risk management, focusing on concise rapid reporting of clinical studies in all therapeutic areas, outcomes, safety, and programs for the effective, safe, and sustained use of medicines. This journal is indexed on PubMed Central, CAS,

\section{Dovepress}

EMBase, Scopus and the Elsevier Bibliographic databases. The manuscript management system is completely online and includes a very quick and fair peer-review system, which is all easy to use. Visit http://www.dovepress.com/testimonials.php to read real quotes from published authors. 